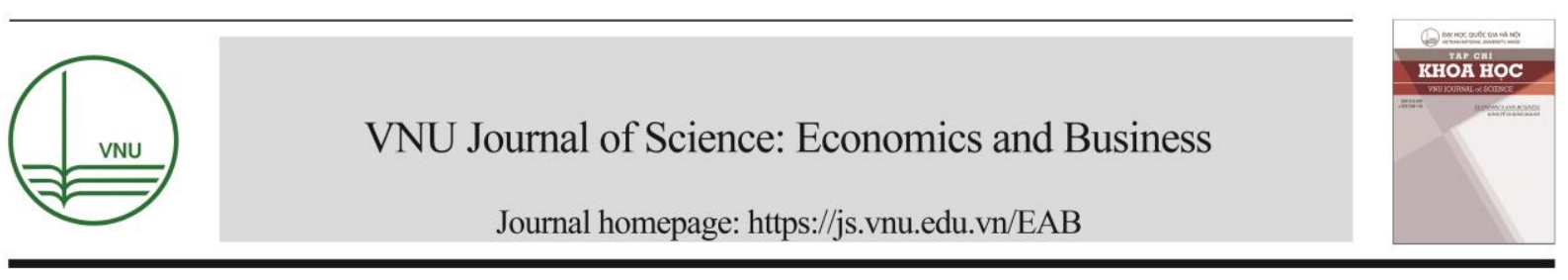

Original Article

\title{
Exploring Constraints of Business Productivity in a Province Nearby the Country Capital: The Case of the UK and Vietnam
}

\author{
Christopher Brown ${ }^{1}$, Nguyen Thuc Huong Giang, ${ }^{2, *}$ Tran Thi Huong ${ }^{2}$ \\ ${ }^{1}$ University of Hertfordshire, Hatfield, Hertfordshire, United Kingdom \\ ${ }^{2}$ Hanoi University of Science and Technology, No. 1 Dai Co Viet, Hai Ba Trung Dist., Hanoi, Vietnam
}

Received 27 November 2019

Revised 20 December 2020; Accepted 20 December 2020

\begin{abstract}
In the digital era, the socio-economic and technological environment is changing continuously. Business productivity is becoming a more and more significant issue in the economy and it is essential to find out what motivates and limits productivity. The inequality in economic development of different provinces in each country is getting higher priority of government in both developed and developing countries. In this comparative study, we chose Hertfordshire in UK and Hung Yen in Vietnam, two provinces nearby the capitals of those countries respectively. These provinces have similar geographic characteristics and types of business structure. The study explores the constraints of business productivity. Hung Yen, one of Hanoi's nearby provinces, enjoys spillover benefits from the capital city's development. However, Hung Yen has to face many challenges from its geographical location and a shortage of high-quality human resources (people who tend to work and develop their careers in the capital). The same as Hung Yen, in the UK Hertfordshire is a county adjacent to London and suffers the same challenges related to graduate skills' mobility and productivity gaps in the STEM skilled sectors. The correlation in business development issues between Hertfordshire and London is similar to the one between Hung Yen and Hanoi, in growth, hard-to-fill skills vacancies and productivity. In recent years, Hertfordshire has had numerous achievements in economic development and improved productivity growth. Therefore, the authors have focused on enterprises in these two provinces with their influencing/constraining productivity factors, including: i) innovation and technology through product/service launches; ii) workforce skill gaps; iii) leadership and management constraints; and iv) business constraints. From that, we propose some recommendations to foster business productivity of enterprises located in the two provinces.
\end{abstract}

Keywords: Business, productivity, constraints, factors, Hung Yen, Hertfordshire.

\footnotetext{
* Corresponding author.

E-mail address: giang.nguyenthuchuong@ hust.edu.vn

https://doi.org/10.25073/2588-1108/vnueab.4454
} 


\section{Introduction}

\subsection{Productivity in the Digital Era}

The 21st-century has seen a shift from the industrial revolution to the new economic domination of information technology [31]. In this "digital era", digital technologies play a prominent role in shaping and regulating the behaviors, performances and standards of the societies, communities, organizations, and individuals [20]. Vietnam is assessed to be one of the fastest-growing countries in digital technology development. Vietnam's information technology and e-commerce sector and digital financial services have been welldeveloped over recent years [4].

In the digital era, applying digital technology can help enterprises enhance effectiveness, reduce costs, rationalize labor demand and strengthen innovative activities to better capture opportunities; thus reshaping business models and changing the barriers for integration, improved transparency, and increased firm productivity [21]. In the "Annual economic report of 2019: improving labor productivity in the digital economy", recently, Dat T.T, Thanh T.T et al (2019) showed the positive influence of digital technology on total factor productivity (TFP) [4].

Vietnam is a country with a young, dynamic population that is diligent to learn, research and apply science and technology. It is also situated in a region with rapid digital economic development, having a very fast technology innovation speed delivery. The TFP of Vietnam has increased in recent years, which has helped contribute significantly to the GDP growth of the country.

\subsection{Local Issues for Enterprises in Hertfordshire Addressing Productivity Challenges}

Over the last twenty years, the focus of the UK government's economic policy has been on improving UK growth and productivity [6]. At a national level, the SME community represents over $99.9 \%$ of all businesses in the UK. The UK government's focus before Covid-19 was, and after will be, on increasing the productivity of SME's to both improve UK economic growth and employment opportunities [17]. This same body of research suggests that these businesses also recognize the importance of investing in skills, $\mathrm{R} \& \mathrm{D}$, and general capital assets. Effective supply-side and demand-side policies by the local UK ecosystem both supports enterprises' innovation and export growth aspirations. What is less-known at the local level, is the particular ecosystem characteristics that most influence enterprises' future innovation activities, potential turnover growth, and improved productivity. Hence, the importance of more research investigating this linkage, and particularly at the regional level (e.g. Hertfordshire) [5].

Table 1. TFP growth rate and contribution to Vietnam's GDP from 2011-2017

Unit: \%

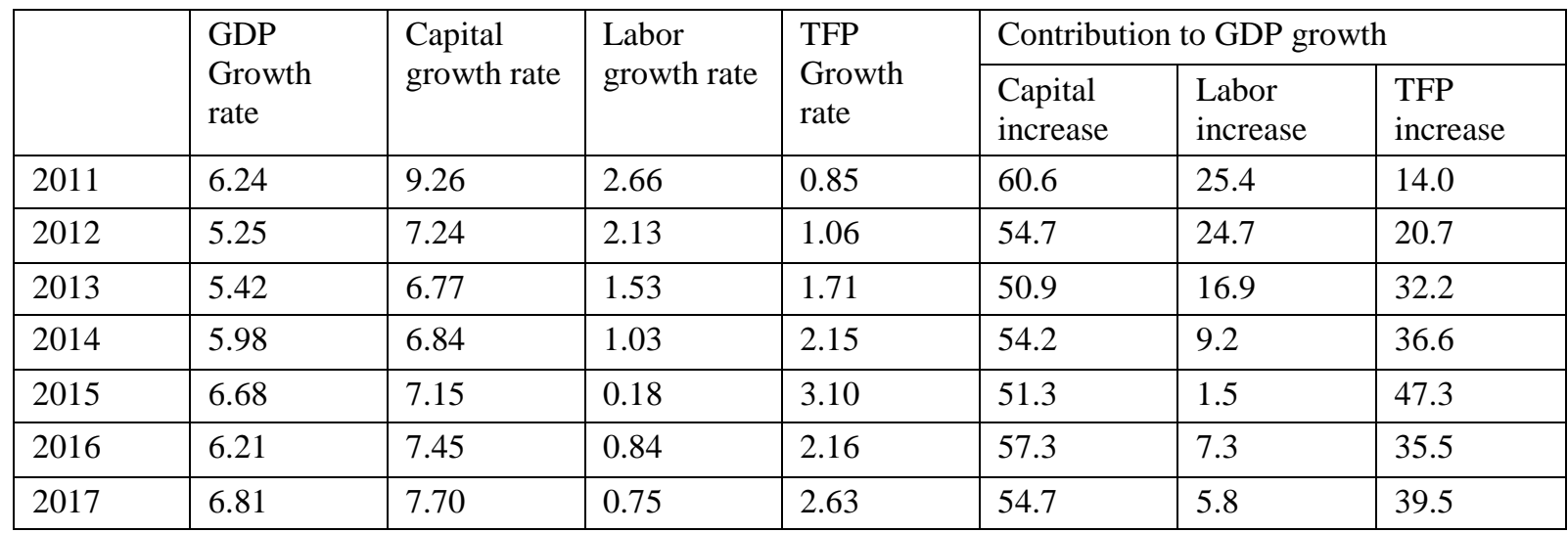

Source: Vietnam Productivity Report 2017, Vietnam Productivity Institute, 2020 [36]. 
Table 2. Hertfordshire businesses, size and sector employment (2020)

\begin{tabular}{|c|c|c|c|c|c|c|}
\hline & \multirow{2}{*}{$\begin{array}{c}\text { Employee } \\
\text { Jobs } \\
\text { Total }\end{array}$} & \multirow{2}{*}{$\begin{array}{c}\text { Hertfordshire } \\
\%\end{array}$} & \multicolumn{4}{|c|}{ Hertfordshire Business Count } \\
\hline & & & $\begin{array}{l}\text { Micro } \\
(0 \text { to } 9)\end{array}$ & $\begin{array}{l}\text { Small } \\
(20 \text { to } 49)\end{array}$ & $\begin{array}{l}\text { Medium } \\
\text { (50 to } 249)\end{array}$ & $\begin{array}{l}\text { Large } \\
(250+)\end{array}$ \\
\hline Manufacturing & 35,000 & $5.5 \%$ & \multirow{10}{*}{58,190} & \multirow{10}{*}{4,615} & \multirow{10}{*}{865} & \multirow{10}{*}{260} \\
\hline Human Health & 58,000 & $9.1 \%$ & & & & \\
\hline $\begin{array}{l}\text { Professional and } \\
\text { Technical }\end{array}$ & 84,000 & $13.2 \%$ & & & & \\
\hline $\begin{array}{l}\text { Information and } \\
\text { Communications }\end{array}$ & 35,000 & $5.5 \%$ & & & & \\
\hline Construction & 42,000 & $6.6 \%$ & & & & \\
\hline Art and Entertainment & 15,000 & $2.4 \%$ & & & & \\
\hline Education & 51,000 & 8.0 & & & & \\
\hline Wholesale and Retail & 105,000 & $16.5 \%$ & & & & \\
\hline Other Sectors & - & - & & & & \\
\hline Total & 637,000 & $100 \%$ & & & & \\
\hline
\end{tabular}

Source: Nomis, Official labour market statistics, Office for National Statistics, UK 2020 [35].

Regionally there are 63,930 enterprises in the Hertfordshire Local Enterprise Partnership area, breaking down into micro-enterprises $(58,190)$, small-enterprises $(4,615)$, mediumenterprises (865), and large enterprises (260) [35]. The Hertfordshire Economic Outlook report of 2018 makes more references to the overall picture of enterprise challenges around innovation, skills, leadership and business strategy [11].

\subsection{Productivity Issues of Enterprises in Hung Yen}

Vietnam is composed of 63 provinces and five centrally-governed cities, including $3 \mathrm{Key}$ Economic Zones (KEZ). The Northern KEZ covers seven cities and provinces, including Hanoi, Hai Phong, Bac Ninh, Hai Duong, Hung Yen, Vinh Phuc, and Quang Ninh. The region accounts for more than $32 \%$ of the country's GDP, with a total land area of $15.755 \mathrm{~km}^{2}$ and a population of 16 million people. The area has seen significant development in the past five to ten years. The GRDP growth of the Northern KEZs from 2011 to 2017 has always been equal to or greater than the annual GDP growth of Vietnam [3].
In this research, the authors chose Hung Yen province to investigate the FTP research problem, against a background of enterprise challenges. According to the Vietnamese Enterprises White Paper (2020), there were 5404 enterprises (2654 micro size, 2066 small, 375 medium, and 309 large size companies) doing business in Hung Yen in 2018 [9]. These enterprises earned 322.801 billion VND in 2018 and increased economic growth by $114.8 \%$ compared to 2017 [9]. Micro-and small-businesses account for the majority of businesses in Hung Yen. However, 75\% of the province's revenue comes from large companies (Table 3).

Located adjacent to the capital city, Hung Yen and other provinces nearby Hanoi have enjoyed spillover benefits from the development of the capital. In recent years, Hung Yen is one of the provinces that has attracted the largest number of foreign investment enterprises to its industrial areas such as Pho Noi A, Thang Long II, Pho Noi Textile and Garment, and Minh Duc industrial zone. However, they have to face many challenges from their geographical location, infrastructure, and a shortage of high-quality 
human resources (people tend to work and develop careers in the capital). The government has pointed out the weakness of the region: i) agricultural production remains scattered; ii) industrial production has mainly expanded horizontally and focused on natural resources exploitation; and iii) high-tech industries, auxiliary industries, logistics, and high-quality services have not developed commensurately with the region's potential [30].

Table 3. Statistics of enterprises in Hung Yen

\begin{tabular}{|c|l|l|l|l|l|l|}
\hline \multirow{2}{*}{ Type of enterprise } & \multicolumn{3}{|c|}{ Number of enterprises } & \multicolumn{3}{c|}{ Net revenue (billion VND) } \\
\cline { 2 - 7 } & $\begin{array}{c}\text { Average } \\
2011-2015\end{array}$ & 2017 & 2018 & $\begin{array}{c}\text { Average } \\
2011-2015\end{array}$ & 2017 & 2018 \\
\hline Classification by size & & & & & & \\
\hline Micro & 1164 & 2161 & 2654 & 2259 & 3787 & 4893 \\
\hline Small & 962 & 1863 & 2066 & 16502 & 32754 & 39381 \\
\hline Medium & 208 & 346 & 375 & 16328 & 33302 & 37057 \\
\hline Large & 179 & 290 & 309 & 69775 & 211414 & 241471 \\
\hline Classification by capital & & & & & & \\
\hline State & 14 & 8 & 8 & 3739 & 782 & 553 \\
\hline Private & 2330 & 4394 & 5138 & 74779 & 217042 & 245544 \\
\hline FDI & 169 & 258 & 258 & 26346 & 63433 & 76704 \\
\hline Total & 2513 & 4660 & 5404 & 104864 & 281258 & 322801 \\
\hline
\end{tabular}

Source: GSO, 2020 [9].

Hertfordshire is a county located $40 \mathrm{~km}$ from central London and Hung Yen is about 60 $\mathrm{km}$ from Hanoi. Both being located near to a capital city, the two provinces have a number of similarities. Hung Yen is a province in the Northern Delta region, in the key economic triangle of Hanoi - Hai Phong - Quang Ninh, and the economic structure is gradually shifting towards industrialization and modernization with many FDI companies choosing to place their organisations/activities in this locality. The province has a long history of development, from the year 1831 when it was first established, later being merged with Hai Duong province in 1968, and then finally re-divided in 1997. It has had much success in attracting investment sources to help develop the infrastructure of industrial parks. However, with the attraction of the capital in drawing a diverse labor force, Hung Yen has had to face a shortage of skilled human resources. In recent years, the province has paid more attention to innovation activities, by organizing Annual
Innovative and Startup Fairs as well as Creative Competitions, which attracts younger people and businesses to the locality.

Hertfordshire has many challenges, its strengths are its successes in being a vibrant county, being adjacent to a world-city (London), boasting significant world-class businesses, world-renowned research centers, comparatively low levels of deprivation, excellent education system, and high economic participation rates. Yet Hertfordshire is not performing to its full potential in terms of underlying productivity rates compared to their world competition [13]. Economic performance was worth $£ 35.6$ billion in 2016, representing $£ 30,600$ per head, this ranking the county as only $27^{\text {th }}$ highest GVA per head across England [12]. Hertfordshire has a high number of enterprises per capita; in 2016 there were 95 active enterprises per 1,000 working age residents, above the UK average of 68 , and with Hertfordshire business survival rates being consistently above the UK average. There are 
149,000 Hertfordshire employees who work in "knowledge-based industries" and "high and medium technology manufacturing", equating to $24.6 \%$ of the total employment in Hertfordshire.

In Hertfordshire the majority of enterprises are in the micro and small size band (98\%); this rate is $88 \%$ in Hung Yen. With all of these similarities between the two provinces/county, an empirical research study exploring the main constraints associated with business productivity in this digital era is both insightful and valuable.

\section{Literature Review}

Productivity is critical to enterprises. It leads to increased profits, potentially higher wages for the workforce and enhanced enterprise competitiveness. There are internal and external factors that influence firm productivity. External factors can be the economic environment, the market situation, government and local regulations. Internal factors include workforce, capital, management and technology. Among these, there are a number of factors that, when they get positive changes, will create a positive effect in enhancing productivity. The inverse is also true; negative changes can make constraints to a firm's productivity too. In this digital era, factors constraining firm productivity may need some adjustments. With the development of science and technology, innovation is the leading factor that influences firm productivity. An empirical research from Lee D. (2016) on the role of $R \& D$ in the productivity growth of Korean industries found that R\&D plays an important role in fostering productivity growth, and the productivity impact of $R \& D$ is stronger in more advanced industries (industries that are close to the technology frontier) and during economic downturns [37]. It is the same with the UK. R\&D is important for both innovation and productivity, while knowledge spillovers are more important than $R \& D$ for firm productivity [2]. Besides innovation and $R \& D$, workforce skills and manager skills also influence the productivity of firms. Workforce skills, number of laborers, and capital intensity are the main factors influencing labor productivity and therefore influence the firm's productivity [4]. Some of the top competencies in the digital era are lifelong learning, personal attitude, teamwork, dependability, and IT foundations [25]. To strengthen the necessary skills for employees in the digital era, training is one of the most important parts of an organization's overall strategy. The need for training arises due to advancements in technology, the need for improving performance or as part of professional development for the employees [33].

Manager skills, ability, and characteristics (such as competency, communication skills, personality traits) can improve employee mental health and enhance firm's productivity [16]. According to Guzman V.E. et al. (2020), leadership is essential to successfully promote a culture of innovation [10]. Leaders assume a crucial role in the paradigm shift towards Industry 4.0. The four leadership skill groups are necessary in the transition process towards Industry 4.0, including: cognitive skills, interpersonal skills, business skills and strategic skills. Hoffman J.M, Mehra S., (1999) showed that the lack of top management support as well as lack of a leadership-based process-oriented environment can discourage success in productivity promotion of the organization [38].

Business constraints are one of the other factors that may constrain the total factor productivity of enterprises, including issues around regulations and policies of the government and local authorities (for example, tax policies, insurances or labor policies, or policies on business registration). Management time invested in political ties weakens the positive relationship between organizational innovation and productivity [19] Complicated public administrative procedures may incur unnecessary costs; high tax and insurance rates can equally create financial difficulties for these businesses. Indirectly, these financial constraints have significant implication for 
firms' productivity growth. Financially constrained firms have lower revenue streams than unconstrained firms [1]. Tax rates, for example with export companies, and export tax rebates can smooth financial constraints through increasing cash flow, substituting working capital, financing fixed assets investment and $R \& D$ investments, and can lead to increased firm productivity [32]. If the government can provide support, it would help to increase firm productivity. However, these effects may vary by country. In the Chinese mixed market, empirical evidence shows that enterprises with government support have increased $R \& D$ spending and thus generally improve their overall productivity [34]. Nevertheless, in Vietnam, there is no evidence of linkage between financial support from the government and firm productivity. Access to financial support improves technological progress and growth in a firm but has a negative impact on improving its technical efficiency [31].

Based on the research studies reviewed, we have defined four main factors that often constrain firm productivity: i) Innovation and technology through product/service launches; ii) Workforce skills gaps; iii) Leadership and management constraints; and iv) general business constraints. The effects of these factors are mainly studied at a national level, hence there is a research gap in exploring these at a local level. These factors should be physically evaluated at the local level to see if, and to what level they influence firm productivity in this digital-era of development and growth, and then suggest mitigating strategies that can improve productivity and performance of these local businesses.

\section{Research Methodology}

\subsection{Research Questions}

As depicted in the above sections, Hertfordshire and Hung Yen county/provinces are facing many challenges in fostering improvements in productivity and economic growth. Therefore, our research focuses on defining the critical factors encouraging and/or constraining the business productivity of enterprises in Hertfordshire through an in-depth research study involving over 436 employers, and then proposes lessons for Hung Yen. To this end, our research paper raises answers to the following research questions:

i) What are the factors constraining business productivity in the digital era, especially of provinces nearby the capital city?

ii) How do the enterprises in Hertfordshire perceive and evaluate these factors? What are the solutions to manage these constraints and improve productivity?

iii) What are the lessons learned for enterprises in Hung Yen province?

\subsection{Data Collection}

The study questionnaire was designed to be sent out to businesses in Hertfordshire (UK). Over 1,000 questionnaires were mailed out and over 436 enterprises responded (for some questions, the rate was a little lower). Almost all respondents were SMEs (more than 90\%). The study questionnaire focuses on seven primary sectors in Hertfordshire: manufacturing \& advanced engineering; life sciences \& pharmaceuticals; professional, financial \& technical services; information, communications \& technology services; construction \& the built environment; arts, entertainment \& recreation services; and highend logistics and retail. These seven sectors are key sectors challenged by the digital transformation process, and acknowledged as pivotal to fuller employment.

The twenty-four key questions in the survey were designed to help understand fully the challenges and issues of productivity, by investigating the driving factors constraining local firm productivity and growth, defining their innovative activities, as well as exploring their upcoming business plan strategies.

Similar to the Hertfordshire study, and with the same objective, we conducted in-depth interviews with middle-level managers of 10 
enterprises in Hung Yen province (Vietnam). Among those 10 enterprises, 50\% were manufacturing and advanced engineering firms. The rest were in Construction, Real Estate, Information and Technology, Logistics and Retail and Financial Services. Forty per cent (40\%) were large-sized businesses, $40 \%$ were SMEs and $20 \%$ were small-and micro-sized businesses. All of the 10 enterprises have worked in Vietnam for more than 8 years. The questionnaires were a little shorter than those in the Hertfordshire survey, but a more detailed explanation of some questions was given. This kind of in-depth interview with middle level managers of the firms and the way of selecting firms to be interviewed in different areas helped collect more detailed explanations than a conventional questionnaire, and also contributed to the reliability of the data collected. Data obtained from the initial survey findings in Hertfordshire helped inform the HUST researchers in their recommendations for improving firm productivity in Hung Yen province.

\subsection{Data Analysis}

Following pilot testing of the Hertfordshire questionnaire, the questionnaire was modified and then transitioned to 'Qualtrics' for deployment to our Tele-marketing researchers. The business respondents' responses were entered into Qualtrics, and after completion imported into SPSS for final data analysis. For the purposes of our initial analysis a crosstabulation approach was used to show the various driving factors of firm productivity against business age, sector and size:

- Business performance

- Expectations of employment growth

- Sales of goods/services outside of the UK

- Business innovative activity

- Workforce skills gaps

- Leaders/managers skills gaps

- Business training plans

- Information sought in last and next year

- Business plans for the next 3-5 years

The data outputs from the cross-tabulation are presented in the section below by grouping the 4 main factors constraining business productivity including; i) innovation and technology through product/service launches; ii) workforce skills gaps; iii) leadership and management constraints; and iv) business constraints.

\section{Main Findings}

\subsection{Business Growth of Surveyed Enterprises}

In 2018, about $90 \%$ of enterprises surveyed had the same or an increase in turnover over the previous year. More than $25 \%$ enterprises had an increase of $10 \%$ or more. The year 2018 can be considered as a good year for local enterprises in Hertfordshire. With 436 enterprises in the seven primary sectors surveyed in Hertfordshire, most experienced over $10 \%$ growth in 2018 . We wanted to understand the key factors behind this good performance.

For 2019, all of the 10 enterprises surveyed in Hung Yen experienced an increase in turnover $(50 \%$ having from $5-10 \%$ turnover increase and 50\% having more than $10 \%$ increase in turnover).

4.2. Perception and evaluation of enterprises in Hertfordshire and Hung Yen about factors constraining their productivity

We synthesize responses of enterprises in Hertfordshire and Hung Yen to analyze 4 main constraints to firm productivity: i) Innovation and technology through product/service launches; ii) Workforce skills gaps; iii) Leadership and management constraints; and iv) Business constraints.

4.2.1. Driving Technology and Innovation through Product/Service Launches

In the Hertfordshire business community, the most important factor driving their current and perceived future performance was their ability to launch new products into the marketplace (Table 4).

The Table 4 shows the importance that Hertfordshire enterprises place on delivering new goods, services and processes to help maintain their competitiveness, sustainability, 
future growth, increased productivity and turnover. Clearly some sectors see the need to create, develop and deliver goods/services that are new to the world, being driven by the latest primary and secondary technologies (Table 5). Nationally, the proportion of SME's that have introduced new or significantly improved goods, services or processes have dropped over the last five years, more so for the micro-and small-enterprises [5]. This suggests that these small enterprises are struggling to resource these developments, either because of lack of relevantly skilled staff and/or the leaders/managers skills in directing and guiding this activity.

Table 4. Introduction of new products/services in the last three years (2017-19)

\begin{tabular}{|c|c|c|c|c|c|c|}
\hline & \multicolumn{4}{|c|}{$\begin{array}{c}\text { Business Size: How many people } \\
\text { do you employ full-time? }\end{array}$} & \multirow[b]{2}{*}{ Total } \\
\hline & & $\begin{array}{l}\text { Micro- } \\
\text { business }\end{array}$ & $\begin{array}{l}\text { Small-sized } \\
\text { Business }\end{array}$ & $\begin{array}{l}\text { Medium- } \\
\text { sized } \\
\text { Business }\end{array}$ & $\begin{array}{l}\text { Large-sized } \\
\text { Business }\end{array}$ & \\
\hline \multirow{2}{*}{$\begin{array}{l}\text { Has your business introduced } \\
\text { any new or significantly } \\
\text { improved goods/services/processes } \\
\text { in the last three years? }\end{array}$} & Yes & 99 & 121 & 60 & 8 & 288 \\
\hline & No & 60 & 64 & 15 & 1 & 140 \\
\hline \multicolumn{2}{|l|}{ Total } & 159 & 185 & 75 & 9 & 428 \\
\hline
\end{tabular}

Table 5. Hertfordshire Enterprises’ Innovation Activity

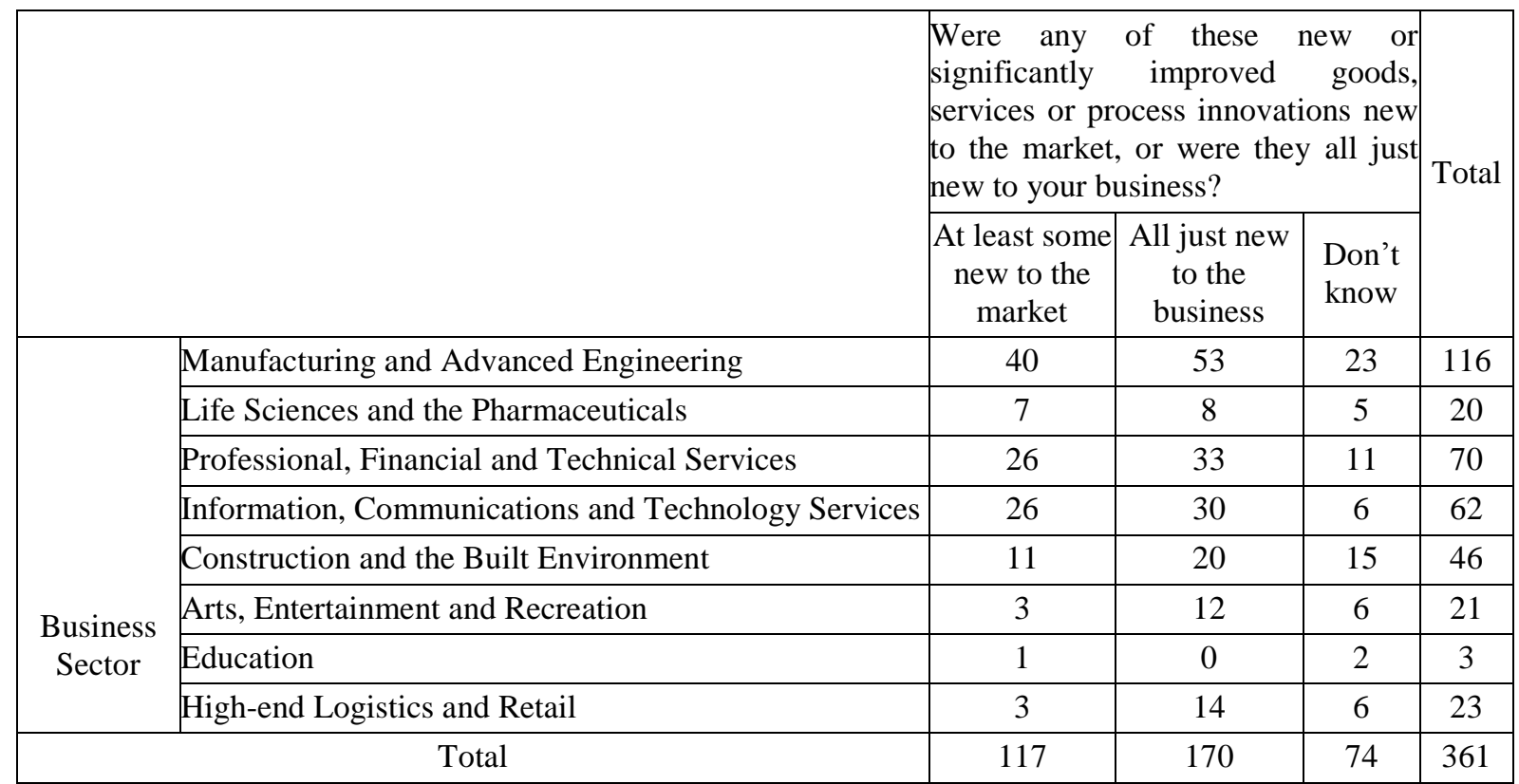

For Hertfordshire enterprises that export to the EU $(36 \%)$ over $74 \%$ of these have introduced a new or significantly improved product/service in the last three years to both help increase turnover and improve productivity. For those Hertfordshire enterprises not exporting (64\%), this drops to $62 \%$.

For those Hertfordshire enterprises that exhibited turnover growth in the last 12 months $(50 \%)$ over $71 \%$ of these had introduced a new product/service in the last 3 years. For those 
predicting turnover growth in the next 12 months (54\%) the introduction of a new product/service over the last 3 years increases to $74 \%$. Both of these facts above supports the national picture of evidence that enterprises that both expose themselves to export markets and have significant innovative activities are more likely to have higher growth and productivity than those enterprises that don't [17].

In Hung Yen, $100 \%$ of surveyed enterprises have introduced new or significantly improved goods/services/processes in the last three years. Sixty per cent $(60 \%)$ of the respondents asserted that their innovations have introduced at least some new goods/services/process to the market, and $40 \%$ of the respondents answered that their innovations were just new to the business. Most of the companies in Hung Yen appreciated the impact of the following related innovation activities: i) External R\&D; ii) Acquisition of external knowledge; iii) Changes in product, service, or process design; and iv) Market research. The proportion of enterprises that evaluated the impact from medium to high was $55.6 \%, 60 \%, 70 \%$, and $80 \%$ respectively.

The budget for research and development of new goods, services, or processes is a critical factor to drive innovation, especially in the digitalization era, when the cost to install and implement digital technology is extremely high. According to our survey in Hung Yen, all businesses doing business in the field of Manufacturing and Advanced Engineering and the fields of Information, Communications, and Technology Services have invested their turnover in $R \& D$ activities with the proportion investing in R\&D being $0-4 \%$ (66.7\% of Manufacturing enterprises) or more than $4 \%(33.3 \%$ of Manufacturing enterprises and all IT companies).

However, according to the project to support Hung Yen Youth startups (2018), most micro, small and new/startup companies in Hung Yen are slow in implementing new technologies in their businesses to help innovate products and services, increasing their competitiveness, and thus enhancing their business efficiency. The two most important reasons are: i) they are facing difficulties in accessing loans and other financial support from the government; and ii) the lack of management and technical skills of staff and managers [15].

4.2.2. Broader Issues of Workforce Skills Gaps

In 2017, the influential 'Employer Skills Survey $2017^{\prime}$ 'suggested that over $20 \%$ of UK employers have unfilled vacancies, an increase year on year over the last five years (Department for Business Innovation \& Skills 2015). The UK as a whole faces a digital skills crisis, where up to 12.6 million of the adult population lack even the basic digital skills (House of Commons 2018). It is estimated that this digital skills gap is costing the UK economy over $£ 63$ billion in lost additional productivity. In the Hertfordshire small enterprise sector, the picture painted is varied and worrying, (see Figure 4 below). In Hertfordshire the difficulties in recruiting appropriately skilled staff are more acute in the small (35\%) and medium-sized (32\%) enterprises (Table 6).

According to our survey in Hung Yen, 90\% of respondents asserted that "Lack of skilled labour" is one of the factors constraining their business turnover/growth and productivity in this digital era. $50 \%$ of the interviewees evaluated the impact as medium, high and very high. One of our respondents stated that: "The biggest hindrance to firm productivity is the lack of highly skilled workers because they are directly involved in the value creation process for the company". $80 \%$ of surveyed companies have increased their number of employees in 2019. However, $90 \%$ of companies worried about the high labour cost impacting their business growth and productivity in this digital era. $70 \%$ of surveyed companies evaluated the performance of their managers in organizing and motivating the staff at a medium or poor level. The same percentage and evaluation was given for the ability to delegate work/responsibility to others. 
Table 6. Common reasons for the employers' workforce skills gaps

\begin{tabular}{|c|c|c|c|c|}
\hline & $\begin{array}{l}\text { Changes } \\
\text { over Year - } \\
\text { Improving }\end{array}$ & $\begin{array}{l}\text { Changes over year - } \\
\text { remaining the same }\end{array}$ & $\begin{array}{c}\text { Changes over } \\
\text { the year - } \\
\text { Deteriorating }\end{array}$ & $\begin{array}{l}\text { Total } \\
\text { Responding } \\
\text { to Question }\end{array}$ \\
\hline Problems in retaining staff & 42 & 340 & 33 & 415 \\
\hline $\begin{array}{l}\text { Increased demands for new } \\
\text { products/services }\end{array}$ & 128 & 269 & 10 & 407 \\
\hline $\begin{array}{l}\text { Introduction of new } \\
\text { technology in the workplace }\end{array}$ & 159 & 231 & 12 & 402 \\
\hline $\begin{array}{l}\text { Unable to recruit new staff } \\
\text { with the necessary skills }\end{array}$ & 49 & 226 & 130 & 405 \\
\hline Staff training not given & 123 & 255 & 3 & 381 \\
\hline $\begin{array}{l}\text { Introduction of new working } \\
\text { practices }\end{array}$ & 151 & 240 & 5 & 396 \\
\hline $\begin{array}{l}\text { Staff skills not improved with } \\
\text { training }\end{array}$ & 119 & 250 & 13 & 282 \\
\hline $\begin{array}{l}\text { Lack of staff motivation for } \\
\text { training? }\end{array}$ & 86 & 285 & 21 & 392 \\
\hline Incomplete staff training & 93 & 278 & 9 & 380 \\
\hline New to role & 97 & 261 & 12 & 370 \\
\hline
\end{tabular}

Decision-making, organizing resources and coordinating tasks, and developing new goods, services or processes that are superior to the competition are three skills that even got the grade "very poor". Most of the respondents considered that the most common reasons for manager skills gaps are as follows:

i) Increased demands for new products/services (30\% of companies stated that the problems remained the same, even deteriorating in 2019);

ii) Introduction of new technology (50\% of companies stated that the problems remained the same, even deteriorating in 2019);

iii) Problems in retaining managers $(75 \%$ of companies stated that the problems remained the same, even deteriorating in 2019); and

iv) Unable to recruit new managers with the necessary skills $(87.5 \%$ of companies stated that the problems remained the same, even deteriorating in 2019).
The above problems are also the common reasons for the skills gaps of staff in Hung Yen. Besides that, being new to the role and incomplete staff training are also significant factors leading to skill gaps.

4.2.3. Leadership and Management Constraints

To understand the perception of enterprises in Hertfordshire on their leaders and managers' performance, the 5-point Likert scale questions were used for respondents, where 1 means very poorly, 2-poorly, 3-average, 4-well and 5-very well. Mean values are almost within the range of 3.5 to 4 , higher than the average level. But as we see in Figure 2 below, on average one in three Hertfordshire enterprises perceive their leaders and managers to be either poor or just average in their performance - significantly so $(42 \%)$ in the area of developing new goods, services or improved processes. 
Table 7. Hertfordshire enterprises' perception of their leaders' and managers' performance

\begin{tabular}{|l|c|c|c|c|c|}
\hline & $\mathrm{N}$ & Min & Max & Mean & Std. Deviation \\
\hline $\begin{array}{l}\text { Identifying goods and services that } \\
\text { deliver real customer benefits? }\end{array}$ & 411 & 1 & 5 & 4.03 & 0.882 \\
\hline Organising and motivating the staff & 412 & 1 & 5 & 3.92 & 0.887 \\
\hline $\begin{array}{l}\text { Delegating work/responsibility to } \\
\text { others }\end{array}$ & 414 & 1 & 5 & 3.82 & 0.984 \\
\hline $\begin{array}{l}\text { Supervising, leading and influencing } \\
\text { the staff }\end{array}$ & 77 & 1 & 5 & 3.53 & 0.954 \\
\hline Decision-making & 414 & 1 & 5 & 3.94 & 0.912 \\
\hline $\begin{array}{l}\text { Organising resources and co- } \\
\text { ordinating tasks }\end{array}$ & 410 & 1 & 5 & 3.98 & 0.873 \\
\hline $\begin{array}{l}\text { Developing new goods, services or } \\
\text { processes that are superior to the } \\
\text { competition }\end{array}$ & 410 & 1 & 5 & 3.94 & 0.884 \\
\hline
\end{tabular}

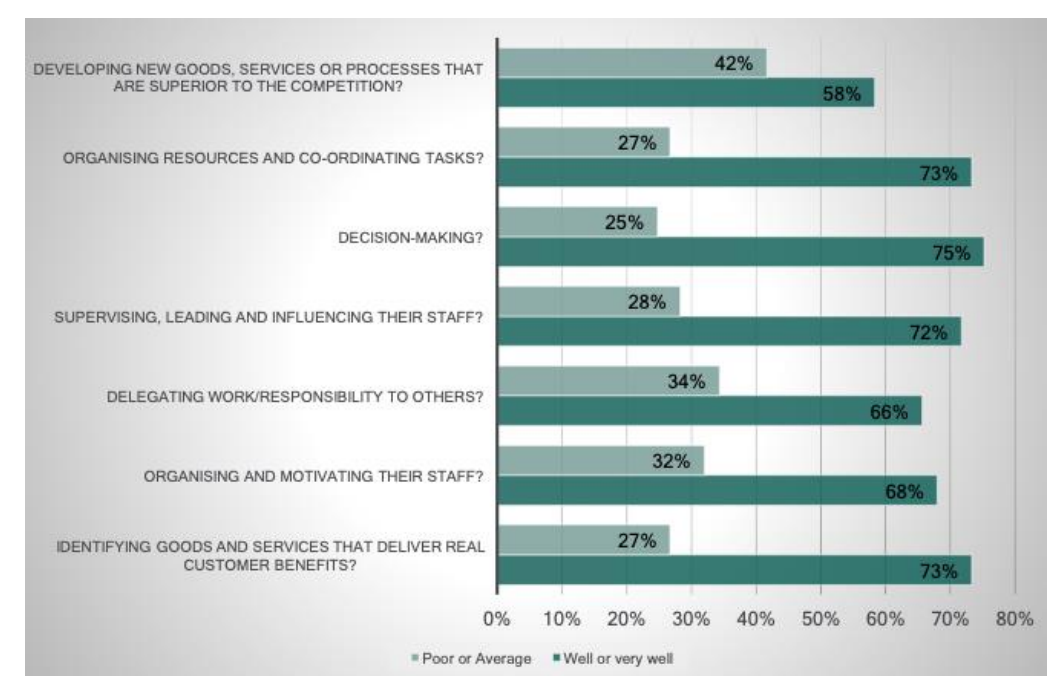

Figure 1. Hertfordshire enterprises' perception of their leaders and managers performance.

In relation to the 10 companies surveyed in Hung Yen province, only 1 of them was having a problem with a manager skills gap, which can constrain the productivity of the company. This company is in the field of Information and Technology, which requires the managers to have very good and updated knowledge on new products and services and the introduction of new technology. Not all the managers of the company can update to the new tendency and new technology application. For them, in the digital age, it is quite difficult for a company to retain good managers as many other competitors are willing to pay a higher salary for high-level managers. And because of the budget capacity, to recruit new highly skilled managers is also one obstacle for the company. Nevertheless, 9 other companies interviewed were not faced with this situation. Even in half of them, the managers' skills have been improved a lot. 
Overall, managers' performance is assessed at an average level. Five companies evaluated their managers as having good decision-making skills, while 3 companies considered their managers' decision-making skills as lower than average. These 5 companies (50\%) also highly appreciated the skills of the managers in developing new products and services and identifying goods and services that deliver real customer benefits in order to enhance competitiveness of the companies. However, 4 other companies assessed their managers as not having skills such as those. Relating to HR management, $40 \%$ of the companies assessed that their managers were good in organising and motivating staff, and having the skills of supervising, leading and influencing staff, delegating work and having responsibility to others, and having capabilities of organising resources and co-ordinating tasks. The $40 \%$ evaluated the above contents at an average level, while $20 \%$ rated the content at a poor level. These were the companies in construction and real-estate industries. In 2018, these 2 industries had a growth rate of $8.02 \%$, higher than the GDP growth rate of the country at $7.08 \%$. The year 2019 was also a year of development for the 2 industries, when the demand for housing and office buildings increased by $19 \%$. However, worker and staff management in these sectors is more difficult, as the human resource structure is complicated, the number of employees is large (both the 2 companies interviewed had more than 300 employees) and numbers often fluctuate. In the digital age, using technology in personnel management in other industries is much easier than in the construction and real estate industries as the work sites are spread out in many locations. This constraint of course influences the management and motivation of the employees by the companies' managers. The $60 \%$ of poor and average level of enterprises interviewed in Hung Yen is much higher than the rate of only from $25 \%$ to $42 \%$ of Hertfordshire. Under the perception of their staff, the managers of enterprises in Hertfordshire have better skills both in HR management and business management. This issue may affect the productivity of Hung Yen companies. To fill the skill gap of the managers, the 10 companies interviewed in Hung Yen stated that they have training plans for managers, as well as budgets prepared for the next coming year (2020).

4.2.4. Business constraints

Table 8 shows the impact level of business constraints on companies in Hertfordshire according to the 5-level Likert scale (1-No impact, 2-Small impact, 3-Medium impact, 4High impact, 5-Very high impact). Mean values are both lower than 3 (medium), but many among those factors made a small to medium impact on enterprises, and the standard deviations are quite high; more than 1 for all of the factors. Issues related to labour force have been analysed in the part above. But related to business constraints, we can see that local enterprises in Hertfordshire have a lot of problems relating to over regulation/red tape and business rates. For the other business constraints such as constraints with premises, IT or transport infrastructure, lack of business support or access to finance/interest rates, the percentage of enterprises having significant impact is lower than $40 \%$ but still high (almost more than $30 \%$, except access to finance/interest rates). Yet with all of these business constraints Hertfordshire enterprises are still predicting strong growth in the coming year, particularly in manufacturing \& advanced engineering (56\%), construction \& the built environment (55\%), information/communications \& technology services $(62 \%)$, and life sciences \& the pharmaceutical (47\%) sectors. In the services industries, arts/entertainment and recreation and high-end logistics \& retail are also predicting strong growth (64\% and 56\%) respectively. Nevertheless, in the digital age, when digital transformation is applied in all the areas of the economy including public service, in one European country, the high rate of enterprises claimed to be affected by these constraints among those surveyed is something that needs to be seriously considered. 
Hung Yen is a province that has just a little progress in PCI ranking, and among 11 Redriver delta provinces, Hung Yen is in the lowest position $\left(11^{\text {th }}\right)$ and ranks $55^{\text {th }}$ in the total of 63 provinces. There are still many business constrains in Hung Yen, such as market entry costs, time costs, proactivity of provincial authorities, business support services and law and order. The marks of some sub-indices such as transparency, unofficial fees and policy bias may even increase but are still low compared to other provinces and to the total average of the 63 provinces (Table 9).

Table 8 . Hertfordshire enterprise perception of factors impacting on productivity and growth

\begin{tabular}{|l|c|c|c|c|c|}
\hline & $\mathrm{N}$ & Min & Max & Mean & Std. Deviation \\
\hline Lack of skilled labour & 431 & 1 & 5 & 2.58 & 1.465 \\
\hline High cost of labour & 430 & 1 & 5 & 2.48 & 1.280 \\
\hline Increasing competition & 428 & 1 & 5 & 2.52 & 1.168 \\
\hline Transport infrastructure & 429 & 1 & 5 & 1.96 & 1.170 \\
\hline Constraint with premises & 427 & 1 & 5 & 1.88 & 1.158 \\
\hline IT infrastructure & 426 & 1 & 5 & 1.85 & 1.068 \\
\hline Attracting and retaining customers & 427 & 1 & 5 & 2.47 & 1.278 \\
\hline Access to finance/ interest rates & 424 & 1 & 5 & 1.63 & 1.007 \\
\hline High cost of energy & 426 & 1 & 5 & 2.02 & 1.209 \\
\hline Over regulation/ red tape & 426 & 1 & 5 & 2.67 & 1.391 \\
\hline Business rates & 423 & 1 & 5 & 2.31 & 1.320 \\
\hline Lack of business support & 428 & 1 & 5 & 1.89 & 1.093 \\
\hline
\end{tabular}

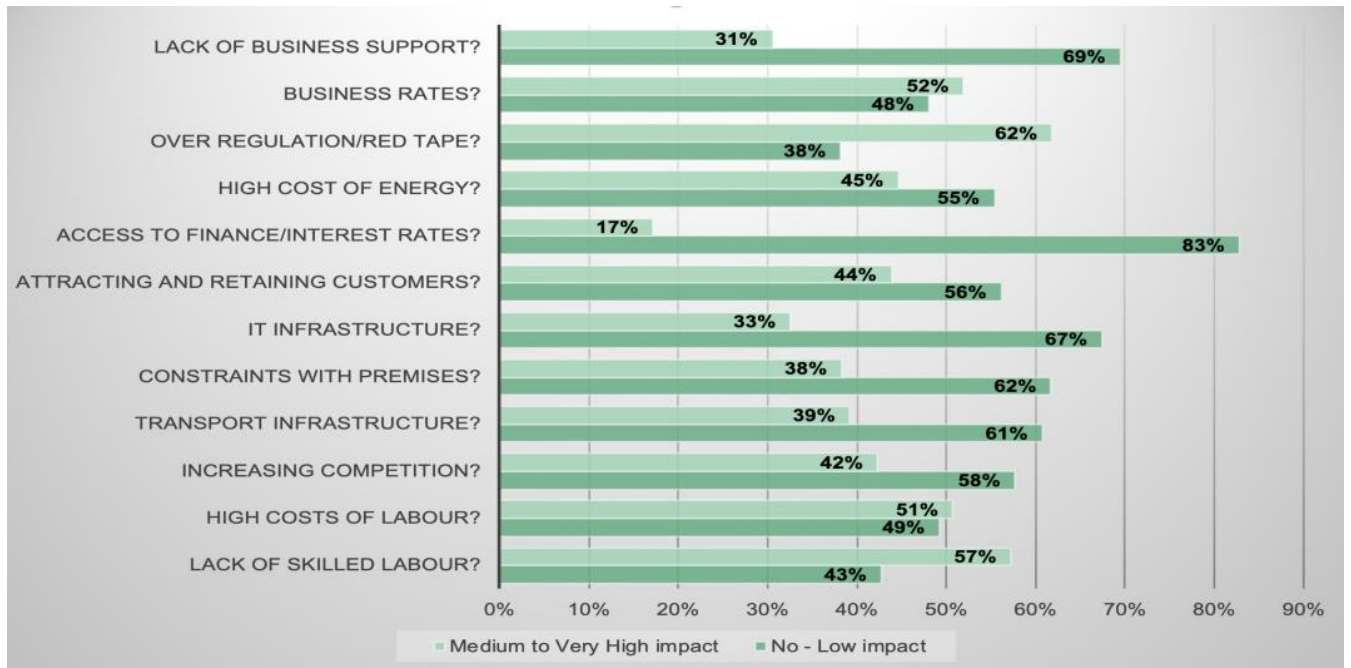

Figure 2. Hertfordshire enterprise perception of factors impacting on productivity and growth. 
Table 9. PCI ranking and business constraint factors of Hung Yen from 2015 to 2019 Unit: 10-point scale

\begin{tabular}{|l|l|l|l|l|l|}
\hline Year & 2015 & 2016 & 2017 & 2018 & 2019 \\
\hline Market entry costs & 8.21 & 8.24 & 7.35 & 7.5 & 6.18 \\
\hline Transparency & 4.88 & 5.68 & 5.62 & 5.5 & 5.98 \\
\hline Time costs & 6.08 & 5.71 & 5.25 & 6.82 & 5.85 \\
\hline Unofficial fees & 4.61 & 5.21 & 4.21 & 4.69 & 6.33 \\
\hline Policy bias & 4.21 & 4.85 & 4.83 & 5.54 & 6.83 \\
\hline Proactivity of provincial authorities & 4.2 & 5 & 4.5 & 6.19 & 5.95 \\
\hline Business support services & 5.18 & 5.23 & 6.38 & 6.41 & 6.17 \\
\hline Law and order & 5.87 & 5.58 & 5.37 & 6.29 & 6.08 \\
\hline PCI (100-point scale) & 55.1 & 57.01 & 59.09 & 60.66 & 63.6 \\
\hline Ranking (in total 63 provinces) & 56 & 50 & 56 & 58 & 55 \\
\hline
\end{tabular}

Source: PCI 2019 report.

The PCI report for 2019 has been done with the survey of thousands of enterprises in the whole country, and with the case of Hung Yen, this result reflects the reality of the local enterprises' difficulties. For the 10 companies interviewed in Hung Yen, 8 companies $(80 \%)$ assess that there is an increase in competition among enterprises. However, the companies that got from medium to very high impacts because of administrative procedures are too many $(90 \%)$.. Other causes of impacts were: lack of business support from the government and local authorities (80\%), difficulty accessing finance resources and preferential interest rates (60\%), and $90 \%$ have problems with high tax rate. It shows that almost all the companies interviewed were having issues with business constraints which were impacting the productivity of their companies. Even 3 of them stated that over-regulation, administrative procedures and red tape are the factors that most affect their company's productivity in the digital age, as it directly influences the company's daily activities.

\section{Discussion, Suggestions and Limitations}

\subsection{Discussion}

According to the data, there are main challenges for the business community in Hertfordshire and their current practices directed towards improving productivity:

i) The Micro-to Medium-sized businesses were $25 \%$ more confident of growing in the next financial year than the larger enterprises. This is linked very closely to their increased investment in capital investments and the general improvement in their workforce skills, through training plans and focused recruitment;

ii) The access of all enterprises to a rich research and information base is critical to their entrepreneurial activity, ability to access skilled human capital, and a highly supportive infrastructure and a rich and appropriate source of business sources;

iii) Clearly, for early age businesses the ability to access finance and equity is critical to their development and growth;

iv) General improvement in management practices is a continual theme in the research findings, suggesting that SME's particularly need to invest in management and leadership training. Here management training colleges and universities hold the key to boosting the management courses suitable for the SME community, and to then inform and identify the quick-wins for their development and growth; 
v) Equally, workforce skills are still challenging for SMEs, particularly in the delivery of "work ready" school/college and university leavers into the employment market. With the focus on productivity and building of STEM-based new businesses, then the focus is on the increasing skills mis-match of graduates and postgraduates in these sectors, and the suggestion of a disconnect between the relevance of STEM programmes in the highereducation sector and Hertfordshire employers skills needs. The increased need nationally for over $3 / 4$ million digitally-skilled workers by 2021 puts pressure on businesses to leverage technology/innovation to both address the increasing challenges of competition, and their own ambitions for growth and increase the opportunity for opening up export markets;

Like Hertfordshire, Hung Yen also has to face many challenges. Even having a good growth level and taking advantage of the province being nearby the capital, challenges also come from these advantages. The issues that many provinces in a developing country like Vietnam have, including the labour skills gap and business constraints, are also the constraints of Hung Yen.

In this digital era, productivity is at the top of all countries' agendas, and as a consequence the internal and external factors identified in this paper, and summarised above are very important and do require the coordination of the supporting agencies to help them address the issue.

\subsection{Suggestions}

The above findings consolidate the similarities and differences between Hung Yen and its forerunner, Hertfordshire, in terms of business productivity. Deriving from the above analysis, we suggest solutions to manage these constraints and improve longer-term productivity for enterprises in Hertfordshire and Hung Yen as follows:

Regarding the business side, enterprises should have a business strategy and plan to:

i) Improve their activities in driving the introduction of new goods/services, on a regular basis, to enhance their abilities to compete in both domestic and overseas markets;

ii) Foster market research to better understand the continuously changing market and develop business strategies that increase the effectiveness of their new goods/service launches;

iii) Push activities of export, e-commerce, and application of digital technologies;

iv) Take part in business networks to learn best practices from their productive and scaledup enterprise neighbours;

v) Pay attention to attract, train, and retain skilled labor (both of managers and staff) through improving compensation policy and the working environment;

vi) Collaborate with university, vocational school, and research institutions to strengthen their human resource and enhance $R \& D$ effectiveness.

Regarding the government side, national and regional governors can support firms through:

vii) Providing sufficient support and advice. In Hertfordshire and Hung Yen, employers that are young and growing search for information on employment, financial and other regulationbased needs, presumably to strengthen their business model and overall business sustainability. As these enterprises mature then they increasingly seek, and prioritise, marketing and market research information needs, better to help fuel their sales pipelines. Figure 4 shows enterprises' information needs by business age. Table 10 shows the evaluation results of business support services of the provincial government in Hung Yen, which fluctuated year by year and depicts quite a low level of governmental supportability.

i) Improving the quality of vocational training, while at the same disseminating industry promotion policies and providing rural businesses with consultancy in the fields of market development and brand building.

ii) Simplifying administrative procedures and regulations and eliminating red tape and bribery evils. 


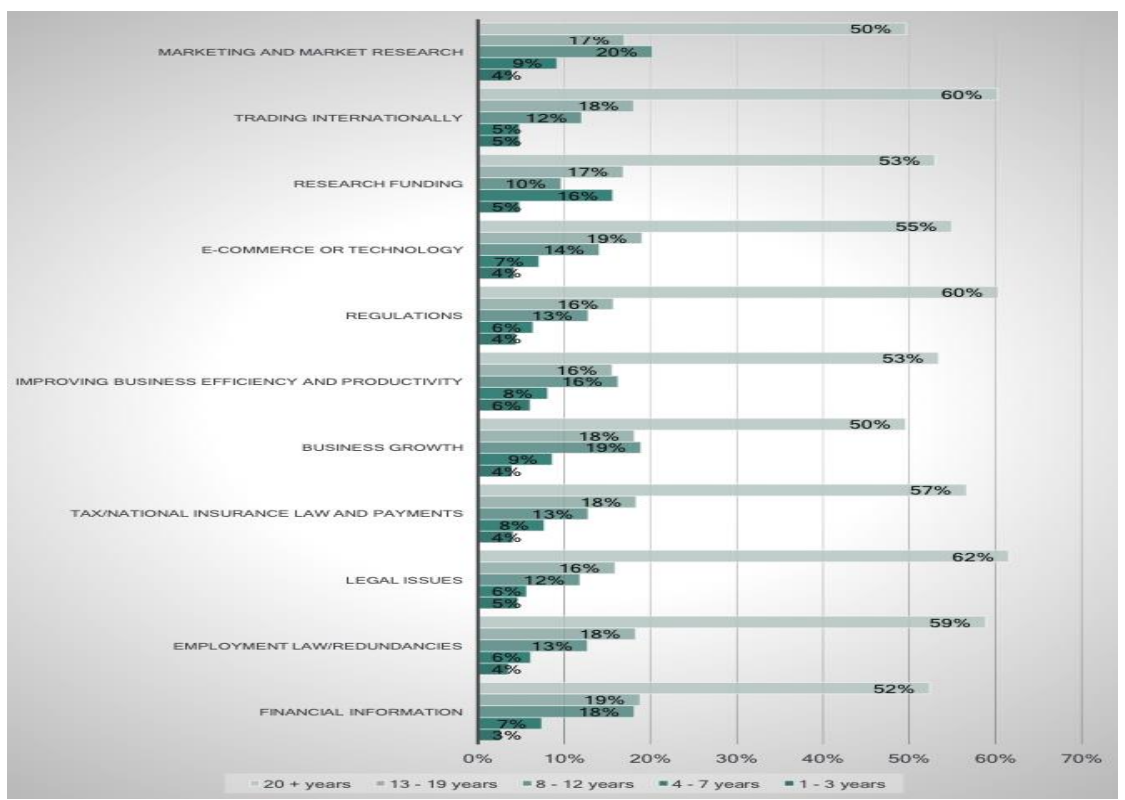

Figure 4. Hertfordshire enterprises' information needs by business age.

Table 10. Evaluation of business support services of provincial government in Hung Yen

\begin{tabular}{|l|l|l|l|l|l|l|l|}
\hline Year & 2013 & 2014 & 2015 & 2016 & 2017 & 2018 & 2019 \\
\hline Business support services & 5.34 & 5.51 & 5.18 & 5.23 & 6.38 & 6.41 & 6.17 \\
\hline
\end{tabular}

Source: PCI Vietnam, 2020.

\subsection{Limitations of Research}

The research still has some limitations. The surveyed timelines were different between the 2 provinces (2019 for Hertfordshire and 2020 for Hung Yen). While the number of samples surveyed in Hertfordshire was over 436 enterprises, due to time scales and the decision to choose an in-depth interview method, we only ran our survey in 10 enterprises in Hung Yen. On the other side, the survey in Hertfordshire covered SMEs, which account for the majority of the local enterprise community, while in Hung Yen, the survey could only be focused on large enterprises and SMEs, when there are a large number of micro-enterprises in Hung Yen. These small types of enterprises do not have much in the way of innovation activities, and do not have many levels of HR management in the organization and do not concentrate on training or improving skills for managers or staff. This is opposite to the case of large enterprises and SMEs. However, although Herfordshire and Hung Yen have different growth levels, they can represent the characteristics of a province nearby the capital, where the number of enterprises is high compared to other regions of the country, and the productivity of the local enterprises play an important role in the development of the provinces in the digital age.

\section{Conclusion}

In every country, national and local government policy is to have an inter-connected strategy on strategic development. Therefore there is a need to have a long-term outlook, to integrate key factors that influence productivity, and then marry this to national strategies [24]. What we present here is identifying the local 
SME community key factors influencing productivity, firstly in Hertfordshire just outside London, and then in Hung Yen, the business community outside Hanoi, Vietnam.

The Hertfordshire productivity study findings have revealed some interesting insights and perspectives of the Hertfordshire SME community, particularly around their activities in driving increased turnover, growth and improved productivity:

i) Hertfordshire SMEs are experiencing steady growth. As a consequence, they are increasingly confident to increase employment levels;

ii) Not surprisingly it is the micro-and small-enterprises who have fewer new goods/services being launched each year compared to medium-enterprises. The STEM skilled sectors have the highest incidence of goods/services launches per year. It is these STEM skilled sectors that more frequently launch new-to-the-world goods/services;

iii) Hertfordshire SMEs that deliver goods, relying on a high STEM skilled workforce, also recognize the high impact of internal $\mathrm{R} \& \mathrm{D}$, and the linked importance of external knowledge acquisition. As a contrast between manufacturing and advanced engineering and professional/financial and technical services, manufacturing firms are twice as likely to have internal R\&D functions than other SMEs;

iv) Hertfordshire micro-and smallenterprises identify the challenge of retaining staff, as having a significant impact on both increasing turnover and on overall productivity;

v) Hertfordshire SMEs reported a worsening of their leaders and managers'ability to cope with introducing new technology, and the increased demand for new goods/services;

vi) Hertfordshire life sciences and the pharmaceutical enterprises cite one of the highest impact constraints being over-regulation/red tape (50\%).

Hertfordshire SMEs' business plans are dominated by the focus on skills gaps and up-skilling their workforce. Key to their future success in turnover, growth and improved productivity, is the ability to recruit and hold on to the right workers. Hertfordshire SMEs' business plans identified the importance of increasing capital investment and investing in increasing the workforce's and leader/managers skills and its linkage to improved productivity. National studies of the Centre for Innovation and Productivity in 2018 suggest a degree of skepticism about enterprises' level of commitment to improving productivity, but our findings suggest differently.

With the case of Hung Yen province in Vietnam, although the companies interviewed had a turnover growth rate in 2019 of more than $5 \%$, the labor skills gap and business constraints impacted total productivity in the digital age the most. A lack of high level staff, high labor costs, over-regulation and red tape that can cause time wasting, staff and losing opportunities for development make Hung Yen one of the least developed provinces in the Red River region (GRDP of Hung Yen ranks at 7th among 11 provinces) and the PCI score ranks the lowest. Simplifying administrative procedures, eliminating red tape, and improving vocational training activities to enhance labor skills are the necessary solutions for enterprises in Hung Yen to ameliorate the actual situation, promote local development and adapt to the requirements of the digital era.

\section{References}

[1] S. Amos, K.A.D. Zanhouo, Financial constraints, firm productivity and cross country income differences: Evidence from sub-Sahara Africa, Borsa Istanbul Review, 2019.

[2] B.D. Audretsch, M. Belitski, The role of R\&D and knowledge spillovers in innovation and productivity, European Economic Review, 2020.

[3] Asia Perspective, Vietnam Key Economic Zones \& Investment Guideline, 2019.

[4] T.T. Dat, T.T. Thanh et al., Annual Assessment of Vietnamese Economy, 2019 Report on "Improving labor productivity in the digital economy”, NEU Publisher, 2019.

[5] Department for Business Energy \& Industrial Strategy, "Longitudinal Small Business Survey: SME employers (businesses with 1 - 249) employeees - UK, 2018", In. London, UK.: BEIS. 
https://assets.publishing.service.gov.uk/governme nt/uploads/system/uploads/attachment_data/file/8 03645/LSBS_2018_employers.pdf/, 2019.

(accessed 5th September 2019).

[6] Department for Business Innovation \& Skills, "Leadership and Management Skills in SMEs: Measuring Associations with Management Practices and Performance", In. London, UK.: BIS, 2015.

https://assets.publishing.service.gov.uk/governme nt/uploads/system/uploads/attachment_data/file/4 18404/bis-15-204-leadership-and-managementskills-in-sme.pdf (accessed 1st December 2018).

[7] Department for Business Innovation and Skills, "Exploring the feasibility of a productivity based approach for evaluating business support interventions", In BIS Research Paper. London, UK.: BIS.

https://assets.publishing.service.gov.uk/governme nt/uploads/system/uploads/attachment_data/file/5 34518/bis-16-311-evaluating-business-supportinterventions-productivity-based-approach.pdf/, 2016 (accessed 1st December 2018).

[8] UK. ERC, "State of Small Business Britain Report 2019", In. Warwick University: Enterprise Research Center.

https://www.enterpriseresearch.ac.uk/wpcontent/uploads/2019/06/02114-State-of-SmallBusiness-Britain-Report_June-2019-Final.pdf/, 2019 (accessed 9th July 2019).

[9] GSO, Vietnamese Enterprise White Paper, 2020.

[10] V.E. Guzman et al., Characteristics and skills of leadership in the context of Industry 4.0, 2020.

[11] L.E.P. Hertfordshire, "Hertfordshire Business Productivity Survey - Interim Report", In. Welwyn Garden City, Hertfordshire, UK.: Hertfordshire Local Enterprise Partnership. https://www.hertfordshirelep.com/, 2019 (accessed 31st May 2019).

[12] L.E.P. Hertfordshire, Grand Challenges for Hertfordshire: towards our local industrial strategy. 12. (accessed 14th December 2020)

[13] Hertfordshire Local Enterpises Partnershi, Hertfordshire Economic Outlook: July 2018. 50 (accessed 28th October 2018).

[14] House of Commons, "Business Statistics." In. London UK.: House of Commons Library. file:///Users/dockitbrown/Downloads/SN06152.pd f/, 2018 (accessed 26th June 2019).

[15] Hung Yen Provincial Youth Union, Project to support Hung Yen Youth startups, Hung Yen Provincial Youth Union, 2018.

[16] S. Kuroda, Yamamoto I., Good boss, bad boss, workers' mental health and productivity:
Evidence from Japan and the World Economy, 2018.

[17] L.H. James, Stephen Roper, "SME Innovation, Exporting and Growth: a review of existing evidence", In. Enterprise Research Centre and Warwick Business School: Enterprise Research Centre. http://enterpriseresearch.ac.uk/wpcontent/uploads/2013/12/ERC-White-PaperNo_5-Innovation-final.pdf/, 2018 (accessed 4th June 2019).

[18] Network, Produtivity Insights, "Productivity Policy Review 2018", In. London UK.: Productivity Insights Network. https://productivityinsightsnetwork.co.uk/2019/01 /productivity-policy-review/, 2019 (accessed 20th June 2019).

[19] C. Li, Enhancing or inhibiting: the impact of investment in political ties on the link between firm innovation and productivity, International Business Review, 2020.

[20] J.P. Liyanage, Hybrid Intelligence through business socialization and networking: managing complexities in the digital era, IGI Global Publisher, 2012.

[21] Mc Kinsey, The rise of Digital Challenges, 2018.

[22] A.S. Min, N. Mansor, R. Anvari, Staff Organization Training: Designing, Stages and Methods, Procedia - Social and Behavioral Sciences, 2014.

[23] PCI Vietnam, PCI of Hung Yen. https://pcivietnam.vn/ho-so-tinh/hung-yen, 2020.

[24] Produtivity Insights Network, "Productivity Policy Review 2018", In. London UK: Productivity Insights Network. https://productivityinsightsnetwork.co.uk/2019/01 /productivity-policy-review/, 2019 (accessed 20th June 2019).

[25] V. Sidoo et al., An exploratory study of digital workforce competency in Thailand, Heliyon, 2019.

[26] UK Department for Business Energy \& Industrial Strategy, "Longitudinal Small Business Survey: SME employers (businesses with 1 - 249) employeees - UK, 2018", In. London, UK.: BEIS. https://assets.publishing.service.gov.uk/government/ uploads/system/uploads/attachment_data/file/803645 /LSBS_2018_employers.pdf/, 2019 (accessed 5th September 2019).

[27] UK Department for Business Innovation \& Skills. 2015. "Leadership and Management Skills in SMEs: Measuring Associations with Management Practices and Performance", In. London, UK: BIS. https://assets.publishing.service.gov.uk/govern ment/uploads/system/uploads/attachment_data/file/4 
18404/bis-15-204-leadership-and-managementskills-in-sme.pdf (accessed 1st December 2018).

[28] UK Department for Business Innovation and Skills, "Exploring the feasibility of a productivity based approach for evaluating business support interventions", In BIS Research Paper, London, UK.: BIS

https://assets.publishing.service.gov.uk/government/ uploads/system/uploads/attachment_data/file/534518 /bis-16-311-evaluating-business-supportinterventions-productivity-based-approach.pdf/, 2016 (accessed 1st December 2018).

[29] UK Commission for Employment and Skills (UKCES), "Anchor institutions and small firms in the UK: A review of the literature on anchor institutions and their role in developing management and leadership skills in small firms", In. London UK.: UKCES.

https://assets.publishing.service.gov.uk/government/ uploads/system/uploads/attachment_data/file/414390 /Anchor_institutions_and_small_firms.pdf/, 2015 (accessed 15th June 2019).

[30] VGP News, Northern key economic zone must maintain leading economic engine status-Northern key economic zone must maintain leading economic engine status. Chinhphu.Vn. http://news.chinhphu.vn/Home/Northern-key- economic-zone-must-maintain-leading-economicengine-status/20196/36919.vgp.

[31] Q. Vu, T.Q. Tran, Government financial support and firm productivity in Vietnam, Finance Research Letters, 2020.

[32] D. Zhang, Can export tax rebate alleviate financial constraint to increase firm productivity? Evidence from China, International Review of Economics \& Finance, 2019.

[33] A. Windsor, Ethical values and resposibles of directors in the digital era, IGI Global Publisher, 2020.

[34] A. Wu, The signal effect of government $R \& D$ subsidies in China: Does ownership matter, Technological Forecasting and Social Change, 2017.

[35] Nomis, Official labour market statistics, Office for National Statistics, UK 2020

[36] Vietnam Productivity Institute, Vietnam Productivity Report of 2017, 2020

[37] D. Lee, The role of $R \& D$ in the productivity growth of Korean industries: technology gap and business cycle", Journal of Asian Economics, 2016.

[38] J.M.Hoffman, S.Mehra, Management leadership and productivity improvement programs, Journal of Applied Quality Management, 1999. 